\title{
Correction to: Trends in U.S. Working-Age non-Hispanic White Mortality: Rural-Urban and Within-Rural Differences
}

\section{Shannon M. Monnat ${ }^{1}$ (D)}

Published online: 24 October 2020

(c) Springer Nature B.V. 2020

\section{Correction to: Population Research and Policy Review https://doi.org/10.1007/s11113-020-09607-6}

In the original publication of the article, Figures 2 and 3 has been published incorrectly. The correct Figs. 2 and 3 are provided here.

The original article can be found online at https://doi.org/10.1007/s11113-020-09607-6.

Shannon M. Monnat

smmonnat@maxwell.syr.edu

1 Lerner Center for Public Health Promotion \& Department of Sociology, Maxwell School of Citizenship and Public Affairs, Syracuse University, Syracuse, NY 13240, USA 
a Metro Non-Hispanic White Males 25-44

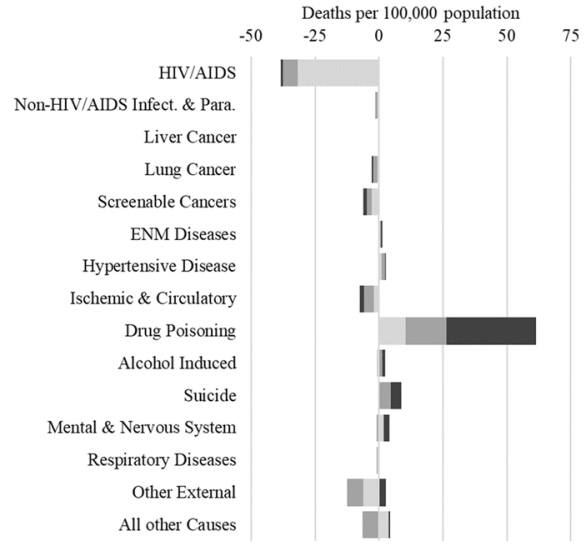

b Nonmetro Non-Hispanic White Males 25-44

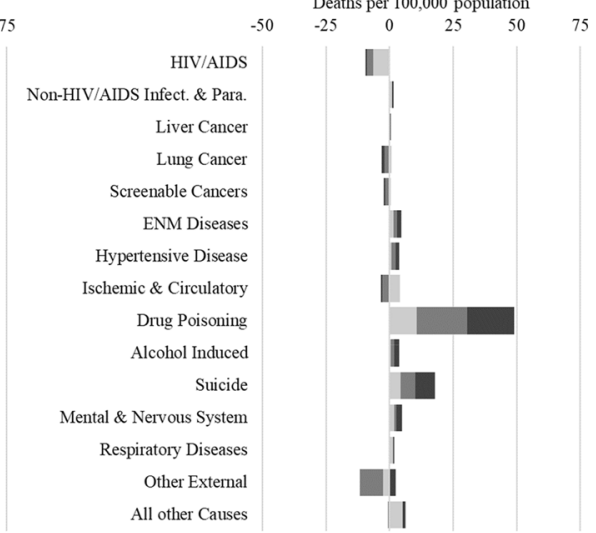

c Metro Non-Hispanic White Females 25-44 Deaths per 100,000 population

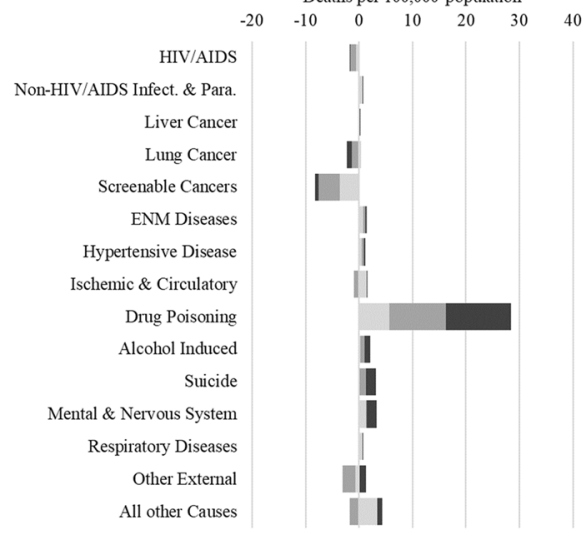

d Nonmetro Non-Hispanic White Females 25-44 Deaths per 100,000 population HIV/AIDS Non-HIV/AIDS Infect. \& Para Liver Cancer Lung Cancer Screenable Cancers ENM Diseases Hypertensive Disease Ischemic \& Circulatory Drug Poisoning Alcohol Induced Suicide Mental \& Nervous System Respiratory Diseases Other External All other Causes

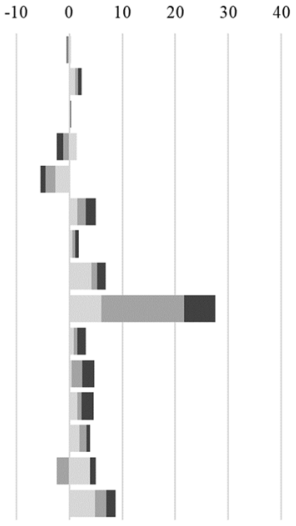

Fig. 2 Decomposition of mortality rate changes by cause of death and by decade for metro and nonmetro $\mathrm{NH}$ white males and females ages $25-44$ 


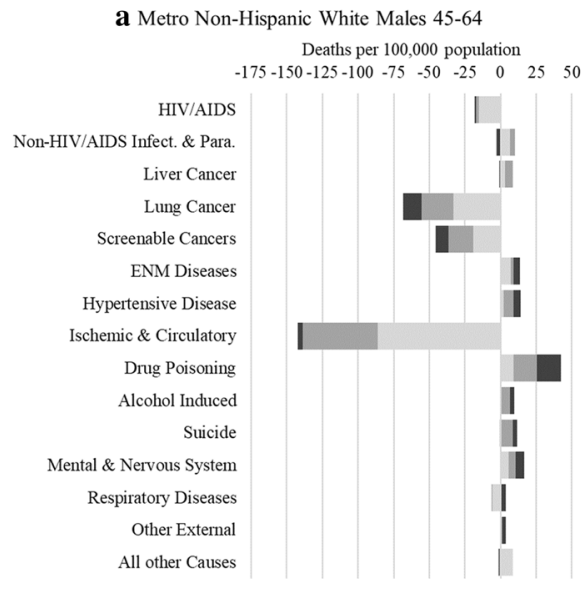

c Metro Non-Hispanic White Females 45-64

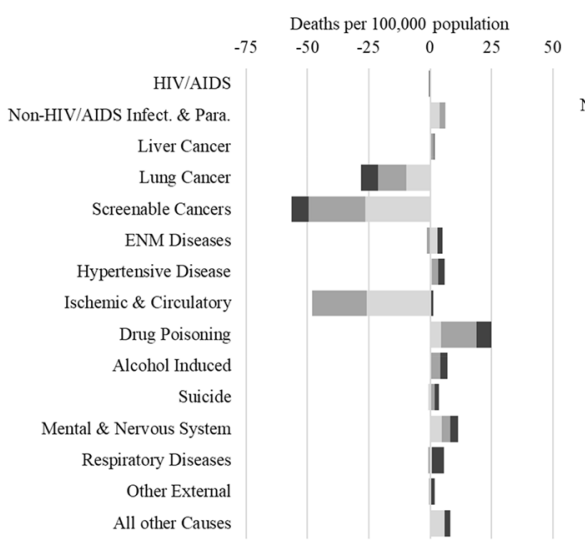

b Nonmetro Non-Hispanic White Males 45-64

Deaths per 100,000 population

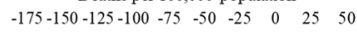

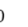

HIV/AIDS

Non-HIV/AIDS Infect \& Pay Liver Cancer Lung Cancer Screenable Cancers ENM Diseases Hypertensive Disease Ischemic \& Circulatory Drug Poisoning Alcohol Induced Suicide

Mental \& Nervous System Respiratory Diseases Other External All other Causes

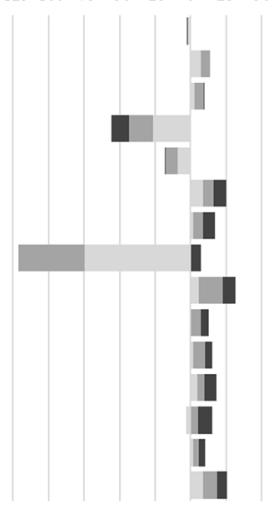

d Nonmetro Non-Hispanic White Females 45-64

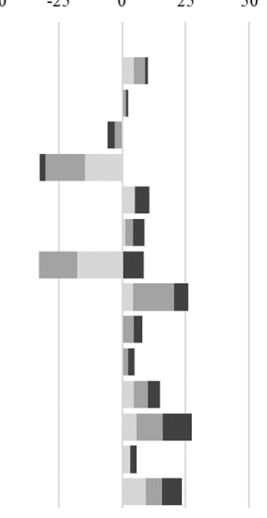

Absolute Change in Mortality Rate
$1990 \mathrm{~s} \quad 2000 \mathrm{~s} \quad 2010 \mathrm{~s}$

Fig. 3 Decomposition of mortality rate changes by cause of death and by decade for metro and nonmetro $\mathrm{NH}$ white males and females ages and 45-64

Publisher's Note Springer Nature remains neutral with regard to jurisdictional claims in published maps and institutional affiliations. 